\title{
Surgical outcomes in phacoemulsification after application of a risk stratification system
}

This article was published in the following Dove Press journal:

Clinical Ophthalmology

15 May 2013

Number of times this article has been viewed

\author{
loannis T Tsinopoulos' \\ Lampros $\mathrm{P}$ Lamprogiannis ${ }^{2}$ \\ Konstantinos T Tsaousis' \\ Asimina Mataftsi' \\ Chrysanthos Symeonidis' \\ Nikolaos T Chalvatzis' \\ Stavros A Dimitrakos' \\ 'Second Department of \\ Ophthalmology, Aristotle University \\ of Thessaloniki, Papageorgiou General \\ Hospital, Thessaloniki, Greece; ${ }^{2}$ First \\ Department of Ophthalmology, \\ Aristotle University of Thessaloniki, \\ AHEPA General Hospital, Thessaloniki, \\ Greece
}

Correspondence: loannis T Tsinopoulos Aristotle University of Thessaloniki, Papageorgiou Hospital, Periferiaki odos, Nea Efkarpia, Thessaloniki 56403, Greece Tel +302313323715

Fax +30 23I 0690417

Email itsinop@med.auth.gr
Background: The purpose of this study was to determine whether application of a risk stratification system during preoperative assessment of cataract patients and subsequent allocation of patients to surgeons with matching experience may reduce intraoperative complications.

Methods: Nine hundred and fifty-three consecutive patients (1109 eyes) undergoing phacoemulsification cataract surgery were assigned to two groups, ie, group A ( $\mathrm{n}=498$ patients, 578 eyes) and group B ( $\mathrm{n}=455$ patients, 531 eyes). Patients from group A were allocated to surgeons with varying experience with only a rough estimate of the complexity of their surgery. Patients from group B were assigned to three risk groups (no added risk, low risk, and moderatehigh risk) according to risk factors established during their preoperative assessment and were respectively allocated to resident surgeons, low-volume surgeons, or high-volume surgeons. Data were collected and entered into a computerized database. The intraoperative complication rate was calculated for each group.

Results: The intraoperative complication rate was significantly lower in group $\mathrm{B}$ than in group $\mathrm{A}$ (group A, 5.88\%; group B, 3.2\%; $P<0.05$ ). Patients from group B with no added risk and allocated to resident surgeons had a significantly lower rate of intraoperative complications than those from group A allocated to resident surgeons (group A, 7.2\%; group B, 3.08\%; $P<0.05$ ).

Conclusion: Our study demonstrates that allocation of cataract patients to surgeons matched for experience according to a uniform and reliable preoperative assessment of their risk of complications allows for better surgical outcomes, especially for resident surgeons.

Keywords: cataract, risk stratification, complications, resident

\section{Introduction}

Cataract removal is a common surgical procedure, both in developed and developing countries, ${ }^{1,2}$ and the frequency with which it is performed has increased dramatically over the last few decades. This trend can be attributed to population aging, increased visual needs, and improved access to high-quality cataract surgery worldwide. Obtaining optimal visual acuity and reducing complications are the main goals for cataract surgeons. It is widely accepted that a thorough preoperative evaluation of cataract patients can meet these goals and contribute to a satisfactory surgical outcome. Identification of risk factors and comorbid conditions having an influence on cataract surgery is a vital part of the preoperative assessment, because it allows patients to be better informed preoperatively as to the complexity of their surgery and the risk of complications. Further, in institutions teaching trainees, a thorough preoperative assessment of the difficulty of the procedure may lead to better selection of cases suitable for teaching purposes. 
Until now, cataract patients in Greek hospitals are allocated to surgeons of varying experience only with a rough evaluation of the difficulty of surgery. Therefore, surgeons with limited experience often encounter cases of increased difficulty, with a high risk of complications. Taking into consideration that most public ophthalmological units are trainee teaching institutions, it is reasonable to expect that surgical outcomes may often fall short of expectations, with a high incidence of complications, poor visual acuity postoperatively, and increased treatment costs. ${ }^{3,4}$ Application of an objective risk stratification system that includes all factors and comorbid conditions known to affect the outcome of cataract surgery may help to determine the difficulty of each case and the potential for complications, allowing patients at higher risk to be operated on by surgeons with greater experience, and rendering complications less likely.

The purpose of this report is to present our results using a validated risk scoring system during preoperative assessment of cataract patients.

\section{Materials and methods}

In this study, we used the risk scoring system described by Muhtaseb et $\mathrm{a}^{5}$ and validated in subsequent studies. ${ }^{6,7}$ Risk factors and comorbid conditions used in the preoperative risk stratification included previous vitrectomy, corneal scarring, small pupil ( $<3 \mathrm{~mm}$ ), shallow anterior chamber (depth $<2.5 \mathrm{~mm}$ ), older age ( $>88$ years), high ametropia ( $>6 \mathrm{D}$ of myopia or hyperopia), posterior capsule plaque, posterior polar cataract, dense/total/white or brunescent cataract, and miscellaneous risks identified by the surgeon, mainly orbital anatomic variations (deep set eyes, prominent brows). The study was approved by the ethics review board at our hospital.

Advanced age and previous information on vitrectomy were obtained from each patient's medical history. Anterior chamber depth and axial length were measured using an optical biometer (IOLMaster ${ }^{\circledR} 500$, Carl Zeiss, Oberkochen, Germany). Corneal scarring, a small pupil, posterior capsule plaque, posterior polar cataract, poor position of eye or patient, dense/total/white or brunescent cataract, pseudoexfoliation, and phacodonesis were screened for during preoperative slit-lamp examination.

In agreement with the scoring system applied, all risk factors were allocated one point each, except dense cataract, pseudoexfoliation, and phacodonesis, which were given three points each (Table 1).

Included in this study were 953 cataract patients (1109 eyes) who underwent phacoemulsification surgery between May 2010 and August 2012. Surgery was performed
Table I Risk factors and comorbid conditions included in the stratification system

\begin{tabular}{ll}
\hline Risk factor or comorbid situation & Points \\
\hline Previous vitrectomy & $\mathrm{I}$ \\
Corneal scarring & $\mathrm{I}$ \\
Small pupil $(<3 \mathrm{~mm})$ & $\mathrm{I}$ \\
Shallow anterior chamber (depth $<2.5 \mathrm{~mm})$ & $\mathrm{I}$ \\
Age $(>88$ years) & $\mathrm{I}$ \\
High ametropia $(>6$ D of myopia or hyperopia) & $\mathrm{I}$ \\
Posterior capsule plaque & $\mathrm{I}$ \\
Posterior polar cataract & $\mathrm{I}$ \\
Dense/total/white or brunescent cataract & 3 \\
Pseudoexfoliation & 3 \\
Phacodonesis & 3 \\
Miscellaneous risks assessed by surgeon & $\mathrm{I}$ \\
\hline
\end{tabular}

on 375 males (aged $70.1 \pm 7.6$ years) and 578 females (aged $72.1 \pm 8.8$ years). The distribution of right and left eyes was 574 right and 535 left. Patients were randomly assigned to two groups, ie, group A ( $\mathrm{n}=498$ patients, 578 eyes $)$ and group $B(n=455$ patients, 531 eyes). A random number generator was used to ensure randomness of the distribution.

Patients underwent phacoemulsification surgery using the "divide-and-conquer" nuclear fracturing technique. All operations used the Infiniti ${ }^{\circledR}$ vision system (Alcon Laboratories Inc, Fort Worth, TX, USA).

Surgeons who performed the operations were categorized into three groups, ie, resident surgeons, low-volume surgeons (performing fewer than 400 cataract surgeries per year), and high-volume surgeons (performing 400 or more cataract surgeries per year). Categorization of surgeons was based on previous studies demonstrating a relationship between surgical experience and outcome of phacoemulsification surgery. ${ }^{8-10}$

Patients from group A were allocated to surgeons based only on a rough preoperative evaluation of surgical complexity. The risk of complications was assessed empirically, without application of an objective stratification system. No distinction was made between cases allocated to low-volume or high-volume surgeons. This type of evaluation is the one currently used in most ophthalmological units in Greece, where cataract surgery is performed by surgeons with varying surgical experience.

Patients from group B were assigned to three groups during their preoperative evaluation according to their risk score. Patients with a risk score of zero (no added risk) were allocated to resident surgeons, patients with a risk score of $1-5$ (low-moderate risk) were allocated to low-volume specialist surgeons, and patients with a risk score of $\geq 6$ (high risk) were allocated to high-volume specialist surgeons. 
Assignment of patients to group A or group B was done in a random manner, without bias or other distortion. Planned extracapsular cataract extractions were not included in this study. No other exclusion criteria were applied.

All study data were entered into a computerized database. Statistical analysis was done using the Statistical Package for Social Sciences version 16.0 for Windows (SPSS Inc, Chicago, IL, USA). Fisher's Exact test was used to detect statistically significant differences between groups.

\section{Results}

All 953 patients underwent phacoemulsification surgery, with 156 having the procedure in both eyes. Hydrophobic (90.8\%) or hydrophilic $(9.2 \%)$ acrylic intraocular lenses were implanted. No lenses were placed in the anterior chamber, but intraoperative complications necessitated placement of 23 three-piece acrylic hydrophobic lenses in the sulcus. The remaining 1086 intraocular lenses were placed in the bag. Topical anesthesia (Visthesia ${ }^{\circledR} 1.0 \%$ containing $0.8 \mathrm{~mL}$ of $1.0 \% \mathrm{NaHa}$ and $1.0 \%$ lidocaine, Carl Zeiss Meditec SAS, La Rochelle, France) with intracameral injection of lidocaine was done in $96.7 \%$ of cases. General anesthesia was necessary in $3.3 \%$ of cases, which were mainly patients suffering from mental illness.

Information on intraoperative complications was extracted from each patient's electronic medical record (operative notes) and entered into a computerized database (Microsoft Excel ${ }^{\circledR} 2007$ for Windows, Microsoft Corporation, Redmond, WA, USA). Anterior chamber hemorrhage, rupture of the posterior capsule, vitreous loss, torn iris, incomplete capsulorhexis, zonule dehiscence, and nucleus drop were recorded.

The surgeries were performed in similar proportions by resident surgeons, low-volume surgeons, and high-volume surgeons in both patient groups (Table 2). No significant statistical differences regarding age and sex were noted between groups A and $\mathrm{B}$.

The overall complication rate for group A was 5.88\% (34/578 procedures). Patients in group A operated on by resident surgeons had a complication rate of $7.22 \%(20 / 277$ procedures), and those operated on by low-volume and

Table 2 Allocation of patients to surgeons with varying experience

\begin{tabular}{lll}
\hline & Group A & Group B \\
\hline Resident surgeons & $277(47.9 \%)$ & $259(48.8 \%)$ \\
Low-volume surgeons & $207(35.8 \%)$ & $181(34.1 \%)$ \\
High volume surgeons & $94(16.3 \%)$ & $91(17.1 \%)$ \\
Total & $578(100 \%)$ & $531(100 \%)$ \\
\hline
\end{tabular}

high-volume specialist surgeons had complication rates of $4.83 \%(10 / 207)$ and $4.25 \%(4 / 94)$, respectively.

The overall complication rate for group B was 3.2\% (17/531 procedures). Patients with no added risk and allocated to resident surgeons had a complication rate of $3.08 \%(8 / 259$ procedures). Patients at low-moderate risk and allocated to low-volume specialist surgeons had a complication rate of $3.31 \%(6 / 181)$ and those at high risk and allocated to highvolume specialist surgeons had a complication rate of $4.4 \%$ (4/91, Figure 1).

A statistically significant $(P<0.05)$ difference in total complication rate was found between group A and group B. Further, group $\mathrm{B}$ patients with no added risk and allocated to resident surgeons had a lower complication rate than their counterparts in group A allocated to resident surgeons. This difference was also found to be statistically significant $(P<0.05)$.

No statistically significant difference in complication rates was found between low-volume and high-volume surgeons, but there was a small increase in complication rates for group B patients operated on by high-volume surgeons. This can be attributed to the greater complexity of cases (risk score $\geq 6$ ) in group $B$ that were exclusively allocated to highvolume surgeons. Complication rates for groups A and B are shown in Table 3. Posterior capsule rupture with or without additional complications (vitreous loss, nucleus drop) was the most common complication (Table 4).

\section{Discussion}

In this study we used a simple, validated, risk stratification method based on previous published data. ${ }^{5-7}$ Preoperative evaluation of patients using this method was found to be uncomplicated and easily integrated in each patient's preoperative assessment. Patient electronic medical record software was modified to support this study, which led

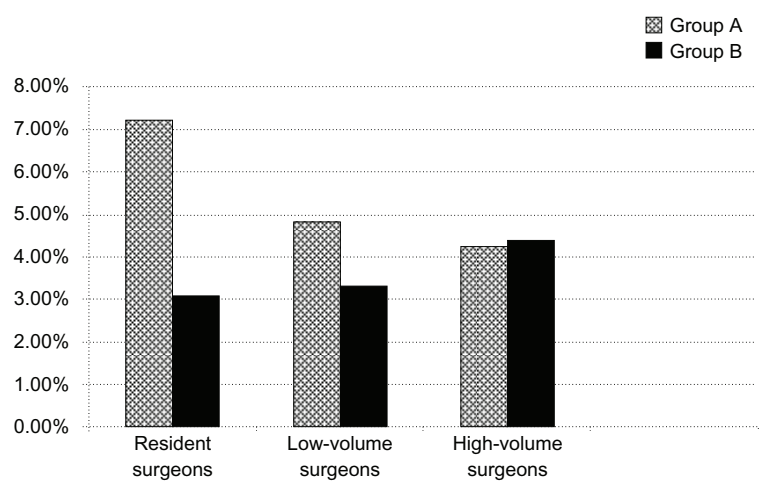

Figure I Rate of complications for each group of surgeons and for both groups of patients. 
Table 3 Rate of complications for groups $A$ and $B$ and for each group of surgeons

\begin{tabular}{|c|c|c|c|c|c|c|}
\hline & \multicolumn{2}{|c|}{ Resident surgeons } & \multicolumn{2}{|c|}{ Low-volume surgeons } & \multicolumn{2}{|c|}{ High-volume surgeons } \\
\hline & Group A & Group B & Group A & Group B & Group A & Group B \\
\hline Posterior capsule rupture & $7 / 277,2.53 \%$ & $4 / 259,1.54 \%$ & $6 / 207,2.90 \%$ & $3 / 181,1.66 \%$ & $3 / 94,3.19 \%$ & $2 / 91,2.20 \%$ \\
\hline Posterior capsule rupture with vitreous loss & $6 / 277,2.17 \%$ & $\mathrm{I} / 259,0.39 \%$ & $2 / 207,0.97 \%$ & $\mathrm{I} / \mathrm{I} 8 \mathrm{I}, 0.55 \%$ & $\mathrm{I} / 94,1.06 \%$ & - \\
\hline Posterior capsule rupture with nucleus drop & $2 / 277,0.72 \%$ & $2 / 259,0.77 \%$ & $2 / 207,0.97 \%$ & $\mathrm{I} / \mathrm{I} 8 \mathrm{I}, 0.55 \%$ & - & $2 / 91,2.20 \%$ \\
\hline Anterior chamber hemorrhage & $\mathrm{I} / 277,0.36 \%$ & - & - & - & - & - \\
\hline Unplanned ECCE & - & - & - & - & - & - \\
\hline Torn iris & $2 / 277,0.72 \%$ & - & - & $\mathrm{I} / \mathrm{I} 8 \mathrm{I}, 0.55 \%$ & - & - \\
\hline Zonular dehiscence & - & - & - & - & - & - \\
\hline Incomplete capsulorhexis & $2 / 277,0.72 \%$ & $\mathrm{I} / 259,0.39 \%$ & - & - & - & - \\
\hline Total & $20 / 277,7.22 \%$ & $8 / 259,3.08 \%$ & $10 / 207,4.83 \%$ & $6 / 181,3.31 \%$ & $4 / 94,4.25 \%$ & $4 / 91,4.40 \%$ \\
\hline
\end{tabular}

Notes: Group A: patients preoperatively evaluated without the application of the risk stratification system. Group B: patients preoperatively evaluated with the application of the risk stratification system.

Abbreviation: ECCE, extracapsular cataract extraction.

to accurate recording of all necessary preoperative and intraoperative data. ${ }^{11}$

Our experience supports the credibility of such a categorization system that includes the majority of factors and conditions known to increase the risk of complications after surgery. A more precise evaluation of the exact odds ratio for a complication conferred by each risk factor, as well as further investigation of other possible risk factors not included in this method may lead to improvements in the credibility of the risk stratification system and, possibly, enhanced overall surgical outcomes. This may need to be the subject of a further multicenter study including a large number of patients, given that cataract surgery is done under a great variety of circumstances. Pseudoexfoliation, for example, is more common in Greek patients $(11.9 \%)^{12}$ than in other white populations. Therefore, Greek cataract surgeons tend to be more acquainted with the potential complications arising with this procedure, which might necessitate an allocation of fewer than three points to pseudoexfoliation as risk factor by Greek surgeons.

The results of this study demonstrate that posterior capsule rupture was the most frequently encountered complication. Further investigation may lead to safer conclusions as to the contribution of each risk factor to the likelihood of this complication.

Further, we suggest that in one-eyed patients, unexpected intraoperative complications in the fellow eye and previous treatment for intraocular melanoma using the charged particle radiation method should be considered as risk factors to be included in the risk scoring system used in this study. Patients

Table 4 Frequency of posterior capsule rupture

\begin{tabular}{lll}
\hline & Group A & Group B \\
\hline Resident surgeons & $15 / 277,5.4 \%$ & $7 / 259,2.7 \%$ \\
Low-volume surgeons & $10 / 207,4.83 \%$ & $5 / 181,2.7 \%$ \\
High-volume surgeons & $4 / 94,4.25 \%$ & $4 / 91,4.4 \%$ \\
\hline
\end{tabular}

Notes: Group A: patients preoperatively evaluated without the application of the risk stratification system. Group B: patients preoperatively evaluated with the application of the risk stratification system. undergoing cataract surgery after treatment of choroidal melanoma have a higher rate of complications because of their increased frequency of preoperative problems, such as rubeosis iridis and posterior synechiae. ${ }^{13}$ Cataract surgery in one-eyed patients puts greater stress on the surgeon, because complications may result in very poor vision for the patient. Previous complicated surgery on the fellow eye may indicate an increased tendency for complications that cannot be attributed to any established risk factor.

Application of this risk stratification system has several advantages. It provides objective information for each patient regarding the likely surgical complexity, which is a vital part of informed consent. ${ }^{14}$ Further, allocation of patients to surgeons with experience matching the difficulty of the procedure reduces the risk of intraoperative complications, thereby improving the outcome of surgery. Reduction of complications leads to better visual acuity and quality of life..$^{15}$

Cost of treatment is another factor that should be taken into consideration. Patients undergoing uneventful phacoemulsification surgery seldom need to be hospitalized, in contrast with complicated cases. Moreover, in the event of complications, additional visits after surgery are needed and redo surgery is often necessary. Therefore, this risk stratification system may result in substantial financial benefits.

Improvement of training for resident ophthalmologists may also be achieved using this method. Better selection of cases suitable for training and a subsequent reduction of complications may improve self-confidence in younger surgeons, although it may be argued that such a risk stratification system excludes residents from undertaking more challenging cases, thereby limiting their surgical training. Categorization of resident surgeons according to their surgical experience and increased flexibility using this method that would allow, for example, a fourth-year resident to perform more complex operations with a risk factor score of one or two could address this potential problem. 


\section{Conclusion}

In conclusion, this validated risk stratification system may become a vital part of preoperative assessment of patients with cataracts and contribute to a uniform and objective assessment of the complexity of each case and the associated risk of complications. Further, this study demonstrates that allocation of patients to surgeons of matching experience leads to better surgical results and improves training for resident surgeons.

\section{Disclosure}

The authors report no conflicts of interest in this work.

\section{References}

1. Murthy GV, John N, Shamanna BR, Pant HB. Elimination of avoidable blindness due to cataract: where do we prioritize and how should we monitor this decade? Indian J Ophthalmol. 2012;60(5):438-445.

2. Tabin G, Chen M, Espandar L. Cataract surgery for the developing world. Curr Opin Ophthalmol. 2008;19(1):55-59.

3. Qatarneh D, Mathew RG, Palmer S, Bunce C, Tuft S. The economic cost of posterior capsule tear at cataract surgery. Br J Ophthalmol. 2012; 96(1):114-117.

4. Malot J, Combe C, Savary P, Moss A, Ligeon-Ligeonnet P, Hida H. Direct cost of cataract surgery in public hospitals. Ann Pharm Fr. 2010; 68(6):380-387. French.

5. Muhtaseb M, Kalhoro A, Ionides A. A system for preoperative stratification of cataract patients according to risk of intraoperative complications: a prospective analysis of 1441 cases. Br J Ophthalmol. 2004;88(10): $1242-1246$.
6. Agrawal V, Upadhyay J; Indian Cataract Risk Stratification Study Group. Validation of scoring system for preoperative stratification of intra-operative risks of complications during cataract surgery: Indian multi-centric study. Indian J Ophthalmol. 2009;57(3):213-215.

7. Osborne SA, Adams WE, Bunce CV, Fraser SG. Validation of two scoring systems for the prediction of posterior capsule rupture during phacoemulsification surgery. Br J Ophthalmol. 2006;90(3): 333-336.

8. Schein OD, Steinberg EP, Javitt JC, et al. Variation in cataract surgery practice and clinical outcomes. Ophthalmology. 1994;101(6): 1142-1152.

9. Bell CM, Hatch WV, Cernat G, Urbach DR. Surgeon volumes and selected patient outcomes in cataract surgery: a population-based analysis. Ophthalmology. 2007;114(3):405-410.

10. Habib M, Mandal K, Bunce CV, Fraser SG. The relation of volume with outcome in phacoemulsification surgery. Br J Ophthalmol. 2004;88(5): 643-646.

11. Chiang MF, Boland MV, Brewer A, et al. Special requirements for electronic health record systems in ophthalmology. Ophthalmology. 2011;118(8):1681-1687.

12. Anastasopoulos E, Topouzis F, Wilson MR, et al. Characteristics of pseudoexfoliation in the Thessaloniki Eye Study. J Glaucoma. 2011; 20(3):160-166.

13. Wachtlin J, Bechrakis NE, Schueler AO, Helbig H, Bornfeld N, Foerster MH. Phacoemulsification following treatment of choroidal melanoma. Graefes Arch Clin Exp Ophthalmol. 2000;238(12): 942-948.

14. Yoshida A. The importance of informed consent in the field of ophthalmology. Hokkaido Igaku Zasshi. 1998;73(1):15-20. Japanese.

15. Garcia-Gutierrez S, Quintana JM, Aguire U, et al. Impact of clinical and patient-reported outcomes on patient satisfaction with cataract extraction. Health Expect. July 11, 2012. [Epub ahead of print.]
Clinical Ophthalmology

\section{Publish your work in this journal}

Clinical Ophthalmology is an international, peer-reviewed journal covering all subspecialties within ophthalmology. Key topics include: Optometry; Visual science; Pharmacology and drug therapy in eye diseases; Basic Sciences; Primary and Secondary eye care; Patient Safety and Quality of Care Improvements. This journal is indexed on

\section{Dovepress}

PubMed Central and CAS, and is the official journal of The Society of Clinical Ophthalmology (SCO). The manuscript management system is completely online and includes a very quick and fair peer-review system, which is all easy to use. Visit http://www.dovepress.com/ testimonials.php to read real quotes from published authors. 